\title{
Análise faciológica e estratigráfica da planície costeira de Soure (margem leste da ilha de Marajó-PA), no trecho compreendido entre o canal do Cajuúna e o estuário Paracauari
}

\author{
Carmena Ferreira de FRANÇA ${ }^{1}$, Pedro Walfir Martins e SOUZA FILHO ${ }^{1}$, Maâmar EL-ROBRINI ${ }^{1}$
}

\section{RESUMO}

A planície costeira de Soure, na margem leste da ilha de Marajó (Pará), é constituída por áreas de acumulação lamosa e arenosa, de baixo gradiente, sujeitas a processos gerados por marés e ondas. Suas feições morfológicas são caracterizadas por planícies de maré, estuários, canais de maré e praias-barreiras. A análise faciológica e estratigráfica de seis testemunhos a vibração, com profundidade média de $4 \mathrm{~m}$, e de afloramentos de campo permitiu a caracterização dos ambientes deposicionais, sua sucessão temporal e sua correlação lateral, a elaboração de seçôes estratigráficas e a definição de uma coluna estratigráfica. Foram identificadas cinco associações de facies: (1) facies de planície de maré, (2) facies de manguezal, (3) facies de barra de canal de maré, (4) facies de praia e (5) facies de duna. A história sedimentar da planície costeira de Soure é representada por duas sucessōes estratigráficas: (1) a sucessão progradacional, constituída pelas associações de facies de planície de maré, manguezal e barra de canal de maré; e (2) a sucessão retrogradacional, formada pelas associaçôes de facies de praia e de duna. Essas sucessões retratam uma fase de expansão das planícies de maré e manguezais, com progradação da linha de costa (Holoceno médio a superior), e uma posterior fase de retrogradação, com migração dos ambientes de praias e dunas sobre depósitos lamosos de manguezal e planície de maré, no Holoceno atual. A história deposicional da planície costeira de Soure é condizente com o modelo de evolução holocênica das planícies costeiras do nordeste paraense.

PALAVRAS-CHAVE

Ambiente deposicional, Holoceno, facies estratigráficas, Amazônia.

\section{Faciological and stratigraphical analysis of Soure's coastal plain (eastern Marajó island-Pará), between Cajuúna channel and Paracauari estuary}

\begin{abstract}
Soures's coastal plain, eastern Marajó island (Pará), is formed by muddy and sandy deposits, low gradient areas submitted to tidal and wave processes. The morphological features are tidal flats, estuaries, tidal channels and barrier-beach ridges. The faciological and stratigraphical analysis of six vibra-core with medium deph of four meters and from outcrops allowed a caracterization of depositional environments, temporal sequence and spacial corelation, the elaboration of stratigraphical seccions and column. Were identified five facies associations: (1) tidal flat facies, (2) mangrove facies, (3) tidal channel bar facies, (4) beach facies and (5) dune facies. The sedimentary history of the Soure coastal plain is represented by two stratigraphical successions: (1) progradational succession (tidal flat, mangrove and channel bar facies association) and (2) retrogradational succession (beach and dune facies association). These successions are related to a expansion phase of tidal flats and mangroves with progradation of the coastline (Middle/Late Holocene) and a posterior retrogradation phase with landward migration of the shoreline (Late Holocene). The depositional history of the Soure coastal plain is related to the holocenic evolution model of the northeast coastal plains of Pará.
\end{abstract}

\section{KEYWORDS}

Depositional environment, Holocene, stratigraphical facies, Amazon.

\footnotetext{
1 Universidade Federal do Pará, Departamento de Geografia. Av. Augusto Corrêa 1, CP 1611, 66075-110, Belém-Pará. e-mail: carir@nautilus.com.br, walfir@ufpa.br, robrini@ufpa.br.
} 


\section{INTRODUÇÃo}

A evolução holocênica da planície costeira do nordeste do Estado do Pará tem sido estudada por vários autores à luz da estratigrafia de seqüências, da morfoestratigrafia e da palinologia (Souza Filho, 1995; Silva, 1996; Souza Filho \& El-Robrini, 1996; Santos, 1996; Silva, 1998; Souza Filho \& El-Robrini, 1998; Silva Júnior \& El-Robrini, 2001; Behling \& Costa, 2001; Senna \& Absy, 2002). Esses trabalhos buscam reconstituir os ambientes deposicionais pretéritos, através da análise das facies sedimentares e da sucessão palinológica.

As sucessões estratigráficas e os dados palinológicos, interpretados na costa paraense, indicam uma evoluçāo controlada pelas flutuações do nível do mar, distinguindo-se três importantes episódios durante o Holoceno. A transgressão marinha, do Holoceno inferior (7.000-6.000 anos A.P.), que resultou no desenvolvimento de bosques de mangues, com predomínio do gênero Rhyzophora. A regressão marinha, que marcou o Holoceno médio (6.000-3.000 anos A.P.), reduziu a área de dominância dos manguezais, permitindo a expansão de pântanos de água doce ou igapós, dominando gêneros como Symphonia, Ilex e Mauritia. E, no Holoceno tardio (2.350 anos A.P.), uma outra fase transgressiva propiciou a substituição dos antigos ambientes de água doce por manguezais, com gêneros botânicos mais diversificados e predomínio de Avicennia e Rhyzophora (Behling \& Costa, 2001; Senna \& Absy, 2002).

A planície costeira de Soure pertence à costa norte-brasileira, dominada por um regime de meso a macromarés, sob a dinâmica da baía de Marajó. Suas feiçōes morfológicas caracterizadas por planícies de maré, manguezais e estuários, bordejados por extensos cordōes de praias-barreiras, guardam semelhanças com os demais setores da costa paraense. A presença de depósitos sedimentares correspondentes e associaçôes de facies similares indicam que a história sedimentar de Soure tem relação com os processos que atuaram ao longo de toda a costa do Pará, durante o Holoceno.

O objetivo deste trabalho foi: (1) caracterizar a planície costeira de Soure, entre o canal do Cajuúna e o estuário Paracauari, sob o aspecto estratigráfico, analisando as associaçōes de facies, a sucessão dos ambientes deposicionais e suas relaçôes laterais; (2) propor uma coluna estratigráfica holocênica; e (3) correlacionar com o modelo de sedimentação proposto para a planície costeira do nordeste do Estado do Pará.

\section{MATERIAL E MÉTODOS}

Foi realizada a revisão crítica das principais publicaçōes e teses relativas à evolução sedimentar holocênica e à descrição das sucessōes estratigráficas da planície costeira do nordeste do Estado do Pará.

Processamento da imagem digital Landsat TM 5 (08/06/ 1995), através do Programa Spring, e obtenção da composição colorida 5R4G3B para a individualização das unidades morfológicas costeiras do município de Soure, entre a foz do canal do Cajúuna e do estuário Paracauari, para a localização dos pontos de amostragem e elaboração do mapa morfológico. A escolha dos locais de amostragens baseou-se na possibilidade de acesso e na distribuição representativa de testemunhos nas porções internas e externas da planície costeira, no trecho considerado.

Realização de seis amostragens a vibração com uma média de $4 \mathrm{~m}$ de profundidade. Os testemunhos foram descritos e analisados com base na metodologia de Figueiredo Júnior (1990), ressaltando-se as estruturas sedimentares, a granulometria e a associação de facies. A análise dos testemunhos permitiu a caracterização dos ambientes sedimentares, a elaboração das seções estratigráficas das porçōes interna, externa e transversal da planície costeira e de uma coluna estratigráfica. Os testemunhos não foram nivelados devido à ausência de dados topográficos.

\section{ÁREA DE ESTUDO}

A planície costeira de Soure está localizada na margem leste da ilha de Marajó, fazendo parte da região estuarina compreendida pela baía de Marajó e adjacências (Figura 1). A região é dominada por um regime de meso a macromarés, cuja variação das marés de sizígia alcança valores máximos entre 3,6 e 4,7 m, entre as ilhas de Mosqueiro e dos Guarás (DHN, 2001).

A planície costeira de Soure é formada por sedimentos argilosos e arenosos holocênicos, de origem flúvio-marinha. As principais unidades morfológicas são representadas por planícies de maré, canais de maré e cordōes de praias e dunas. A cobertura vegetal é constituída predominantemente por manguezais e restingas. Dentre as espécies de mangues, destacam-se: Rhyzophora racemosa G.F.W. Meyer, Rhyzophora mangle L., Avicennia schaweriana Stapf \& Leech, Avicennia germinans L. Stearn e Laguncularia racemosa Gaertn. Nas restingas, são comuns: Chrysobalanus icaco L., Anacardium occidentale L., Paspalum vaginatum Sw., Ipomea pescaprae Rott. e Byrsonima crassifolia (L.) Kunth. (Lisboa et al., 1993).

\section{RESULTADOS E DISCUSSÃO}

\section{ASSOCIAÇÃO DE FACIES ESTRATIGRÁFICAS E AMBIENTES DEPOSICIONAIS DA PLANÍCIE COSTEIRA DE SOURE}

A zona costeira de Soure é constituída por áreas de acumulação lamosa e arenosa, de baixo gradiente, sujeitas a inundaçōes periódicas, relacionadas a processos gerados por marés e ondas. A variação dos processos e do suprimento sedimentar propiciaram o desenvolvimento de vários ambientes deposicionais. Os ambientes de sedimentação lamosos são caracterizados por baixos níveis de energia e por processos dominados por maré, onde o agente de deposição mais importante é representado pelas correntes de maré. As facies sedimentares se definem por estruturas heterolíticas, com espessuras variadas, relacionadas às mudanças 

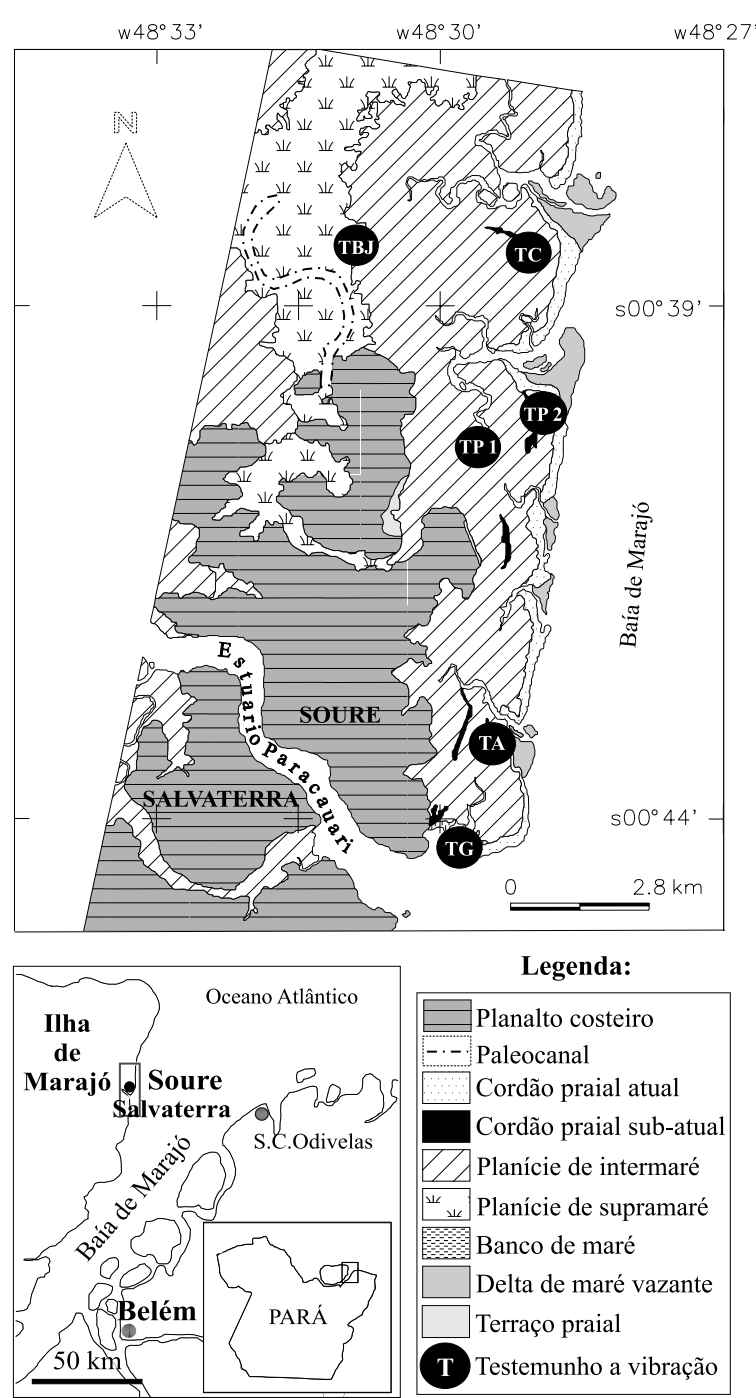

Figura 1 - Mapa morfológico da área de estudo e localização dos testemunhos a vibração.

periódicas na velocidade das correntes, caracterizando unidades ambientais como planícies de maré e manguezais.

Os ambientes de deposição arenosa, representados principalmente pelas praias-barreiras, caracterizam-se por altos níveis de energia, onde os agentes mais atuantes são as correntes de maré e ondas. A estrutura interna das facies reflete estratificaçōes paralelas a inclinadas ou sem estratificaçāoo aparente, decorrentes das condiçôes hidrodinâmicas, do modo de acamamento ou do fluxo de grãos.

As transformações das condições físicas, como a alteração dos fluxos, dos níveis de energia e do fornecimento sedimentar, implicam em mudanças nos ambientes deposicionais, que se sucedem e se preservam no registro geológico (Reinson, 1992).
A análise da evolução da zona costeira está pautada na descrição das diferentes estruturas sedimentares e dos tipos de grãos das camadas depositadas. A correlação lateral e vertical das várias unidades permite a elaboração de seções estratigráficas, fundamentais para a reconstrução dos ambientes deposicionais e sua sucessão ao longo do tempo (Silva, 1996).

\section{DESCRIÇÃO DAS ASSOCIAÇÕES DE FACIES ESTRATIGRÁFICAS}

Com base na litologia, nas estruturas e texturas sedimentares, interpretadas nos testemunhos e em afloramentos de campo, foram identificadas cinco associaçôes de facies estratigráficas, na planície costeira de Soure : (1) facies de planície de maré, (2) facies de manguezal, (3) facies de barra de canal de maré, (4) facies de praia e (5) facies de duna.

As associações de facies são descritas abaixo como:

\section{ASSOCIAÇÃO DE FASCIES DE PLANÍCIE DE MARÉ}

Esta associação constitui-se das seguintes subfacies: (1) lama cinza stripe lamination; (2) areia/lama com acamamento lenticular; (3) lama negra laminada paralelamente; (4) lama cinza escura a negra; (5) areia/lama com estrutura lenticular a wave e marcas onduladas; (6) areia/lama com acamamento wave a flaser.

Os depósitos de planície de maré encontram-se na base e na parte média dos testemunhos da porção interna da planície costeira TBJ e TP1, alcançando profundidades de 2,70 a 4,20 m, e espessuras de 0,50 a $1,75 \mathrm{~m}$. Nos testemunhos da porçãao externa, esses depósitos variam de profundidade, encontrando-se na parte inferior (testemunhos TG e TP2), intermediária (testemunhos TC e TP2) e superior (testemunho TA), com espessuras entre 0,50 e $2,50 \mathrm{~m}$ (Figura 2). As facies de planície de maré apresentam-se, geralmente, em contato gradacional com as facies de manguezal, e em contato abrupto com as facies de cordão praial.

Os ambientes de planície de maré desenvolvem-se em costas dominadas por maré, protegidas por barreiras arenosas. Os baixos níveis de energia e os mecanismos de transporte carreiam sedimentos de granulometria fina (silte, argila e areia fina), que são depositados conforme a diminuição da competência das correntes e durante o estofo da maré. O elevado teor de lama decorre da floculação físico-química das argilas, da formação de organo-argilas e do trapeamento de sedimentos biogênicos (Souza Filho \& El-Robrini, 1996).

Há um padrão de distribuição de sedimentos característico das planícies de maré. Nas porçōes interiores, próximo à linha de maré alta de sizígia e divisores de água, os sedimentos são lamosos em função do tempo mais prolongado de atuação das correntes de baixa velocidade. Próximo à linha de maré baixa, as ondas são mais fortes e atuam por um período mais longo, favorecendo um aumento no teor de areia dos depósitos (Reineck \& Singh, 1980; Dalrymple, 1992). As variaçôes do teor de areia e das estruturas sedimentares possibilitam a identificação das planícies lamosas 
de supramaré, que desenvolvem estruturas do tipo lenticular, stripe lamination e lamas com acamamento paralelo, e planícies de intermaré e inframaré com estruturas heterolíticas do tipo wave eflaser (Souza Filho \& El-Robrini, 1996).

\section{ASSOCIAÇÃO DE FACIES DE MANGUEZAL}

Esta associação é constituída por facies de lama maciça cinza escura a negra e de lama orgânica cinza stripe lamination, com abundância de raízes e outros fragmentos orgânicos. São facies localizadas na porção superior dos testemunhos, com espessuras entre 0,50 a $2,15 \mathrm{~m}$, nos perfis internos da planície costeira (testemunhos TP1 e TBJ), e entre 0,20 a $0,75 \mathrm{~m}$ nos perfis externos (testemunhos TC, TP2 e TA) (Figura 2).

Os processos de sedimentação dos ambientes de manguezal são similares aos descritos anteriormente, porém o que diferencia esses depósitos é a intensa atividade biológica, que desenvolve estruturas mosqueadas e marcas de raízes, destruindo a estratificação original das camadas (Souza Filho \& El-Robrini, 1996).

\section{ASSOCIAÇÃO DE FACIES DE BARRA DE CANAL DE MARÉ}

Esta associação é constituída predominantemente de areias finas, com acamamento heterolítico wave a flaser, intercaladas com facies de estratificação plano-paralela a inclinada de baixo ângulo, relativa à migraçăo lateral dos sedimentos no interior dos canais de maré. São facies que se encontram no topo do testemunho TP1 até a profundidade de $1,10 \mathrm{~m}$ (Figura 2).

\section{ASSOCIAÇÃO DE FACIES DE PRAIA}

Esta associação caracteriza-se por areias finas (2,98f), muito bem selecionadas $(0,32 \mathrm{f})$, apresentando estratificação planoparalela a inclinada de baixo ângulo, algumas vezes intercaladas com camadas delgadas de estratificação heterolítica wave e flaser. São facies arenosas com espessuras entre 0,70 a 2,25 m, nos testemunhos da porção distal da planície costeira.

Os processos de deposição, nos ambientes praiais, são controlados pela ação das ondas e correntes de maré, que retrabalham o suprimento sedimentar ao longo da costa, transportando em suspensão os materiais mais finos (silte/argila) e depositando os mais grossos, resultando num empilhamento arenoso.

As cristas arenosas são comuns em áreas de estuários e em costas abertas dominadas por maré, formando corpos alongados separados por canais de maré. A formação de praias-barreiras permite o desenvolvimento de lagunas e manguezais, entre a praia e o continente, tendo os sedimentos das porçôes internas cercados e interdigitados com sedimentos da planície lamosa (Dalrymple, 1992).

\section{ASSOCIAÇÃO DE FACIES DE DUNA}

Esta associação de facies é constituída de areias finas (2,84f),
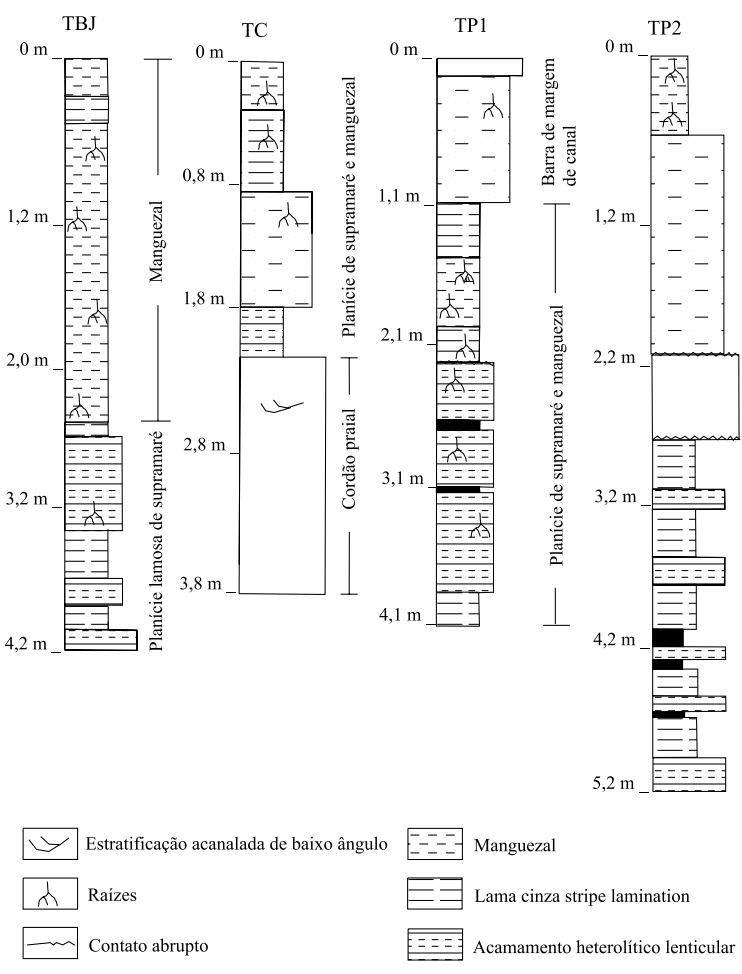

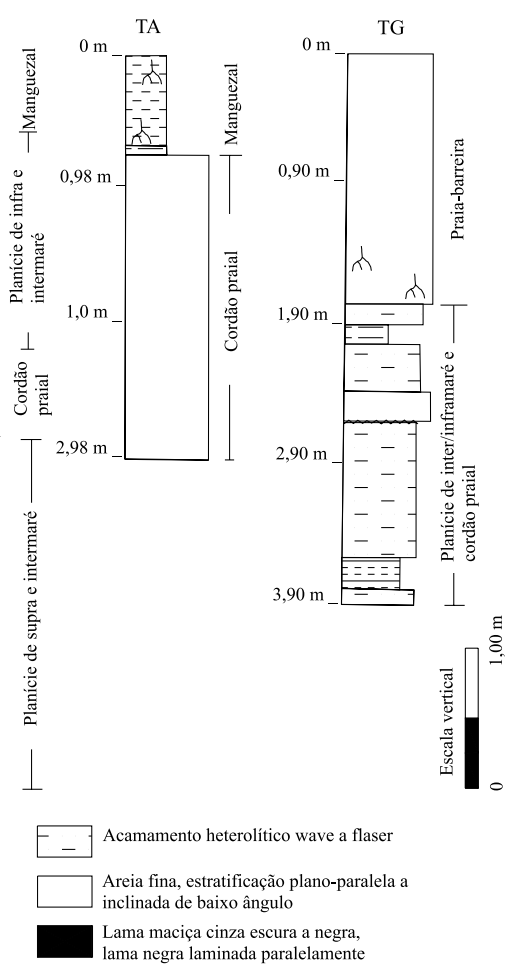

Figura 2 - Seções estratigráficas ilustrando as associações de fácies da planície costeira de Soure, com base na interpretação dos testemunhos a vibração. 
muito bem selecionadas $(0,27 \mathrm{f})$, com estratificação inclinada de baixo ângulo, formando estratos de pequeno porte.

Os processos de deposição são controlados pela ação dos ventos, que retrabalham os sedimentos praiais expostos durante a maré baixa e os transportam para a região compreendida entre o manguezal e a pós-praia. A superposição das camadas sedimentares ocorre por precipitação e deslizamento das areias na área de sotavento das dunas (Silva, 1996).

Em Soure, as dunas são longitudinais à linha de costa e recobertas por vegetação arbustiva e herbácea.

\section{SUCESSÃO DE AMBIENTES DEPOSICIONAIS NA PLANÍCIE COSTEIRA DE SOURE}

A análise da associação de facies permite definir a sucessão dos ambientes deposicionais e sua distribuição nas porçôes internas e externas da planície costeira de Soure.

Os perfis internos são representados pelos testemunhos TBJ e TP1 (Figura 3). Apresentam facies de planície lamosa de supramaré na base dos testemunhos, com espessuras de 1,60 e 1,80 m. No TBJ, realizado a $4 \mathrm{~km}$ de distância da linha de costa atual, a planície de supramaré grada para depósitos de manguezal com 2,15 $\mathrm{m}$ de espessura, marcando a parte superior do testemunho. No TP1, distante cerca de $1,33 \mathrm{~km}$ da linha de costa atual, o limite superior da planície de supramaré é marcado por um contato abrupto $(2,15 \mathrm{~m}$ de profundidade) com os depósitos sobrejacentes de manguezal. Estes apresentam espessura de $0,75 \mathrm{~m}$ e gradam novamente para planície lamosa de supramaré. Na parte superior, a planície lamosa é substituída por facies granocrescentes ascendentes.

A sucessão de facies, dos testemunhos internos (TBJ e TP1), registra uma granodecrescência ascendente, com progradação final do ambiente de manguezal sobre o ambiente de planície de maré lamosa, indicando a maior espessura dos depósitos lamosos, na porção interna da planície costeira. A localização do TP1 na margem direita do canal do Pesqueiro revela uma fase progradacional da planície de maré e manguezal, sobreposta por facies granocrescentes ascendentes, relativas à formação de uma barra areno-lamosa de margem de canal.

Os perfis estratigráficos externos, da planície costeira de Soure, são representados pelos testemunhos TC, TP2, TA e TG, coletados próximo à atual linha de costa (Figura 4). Constituemse de facies mais arenosas, relativas a ambientes de inter e inframaré e cordão praial, com espessuras variadas.

O TC, realizado a $615 \mathrm{~m}$ de distância da linha de costa, registra dois ciclos de empilhamento granodecrescente ascendente, da base para o topo, que caracterizam a sucessão de antigos ambientes praiais e planícies areno-lamosas de inframaré por ambientes de planície lamosa de supramaré, registrando no topo a progradação de manguezal. Essa sucessão representa as mudanças das condiçōes físicas ambientais, como a alternância do nível de energia e do aporte sedimentar, ao longo do tempo, propiciando fases de deposiçāao arenosa e fases de deposição lamosa.

OTP2, localizado a poucos metros da praia do Pesqueiro, também registra pulsos progradacionais alternados entre a planície de maré e o cordão praial. A parte inferior do testemunho é marcada por depósitos heterolíticos, com espessura de $2,5 \mathrm{~m}$, característicos de ambiente de supramaré/intermaré. A parte intermediária é marcada por um contato abrupto $(2,60 \mathrm{~m}$ de profundidade), quando a planície de maré é sobreposta por um cordão arenoso praial, com $0,60 \mathrm{~m}$ de espessura. Outra passagem abrupta (2,0 $\mathrm{m}$ de profundidade) marca a sucessão do cordão praial por planície de inframaré e, no topo do testemunho, por facies cada vez mais lamosas, relativas a ambientes de planície de intermaré, supramaré e manguezal.BASE

O TA foi coletado a cerca de $190 \mathrm{~m}$ de distância da costa atual. A parte inferior do testemunho mostra uma associação de facies arenosas, que formam um espesso pacote de $1,8 \mathrm{~m}$, relativas a ambiente praial. Facies lamosas sobrepõem-se, no topo do testemunho, constituindo um perfil granodecrescente ascendente, representando a progradação dos ambientes de planície lamosa de supramaré e manguezal sobre os depósitos de antigo cordão praial.

O TG coletado na área lagunar, atrás da praia do Garrote, apresenta na base do testemunho facies areno-lamosas de planície de inframaré, sucedidas por facies arenosa associada a leque de lavagem. Registra-se um contato abrupto entre as facies de planície de inframaré e a facies de leque de lavagem $(2,60 \mathrm{~m}$ de profundidade). Os leques de lavagem, que se estendem para dentro da laguna, constituem-se em corredores de transferência de sedimentos arenosos, provenientes da praia-barreira, formando planícies arenosas. Este éo principal mecanismo de alargamento da barreira, cujo desenvolvimento cria, na porção interna, ambientes favoráveis ao crescimento de pântanos (Reinson, 1992). A facies de leque de lavagem é sobreposta por facies arenolamosas de planície de infra, inter e supramaré, na porção intermediária do testemunho. Para o topo, os depósitos tornamse novamente arenosos, formando um pacote de $1,78 \mathrm{~m}$ de espessura de areia fina cinza clara a esbranquiçada. A sucessão de facies retrata um perfil granocrescente ascendente, representando a alternância da planície de maré e do cordão arenoso, e a instalação definitiva da praia do Garrote no topo.

\section{SEÇÕES ESTRATIGRÁFICAS DA PLANÍCIE COSTEIRA DE SOURE}

A interpretação e a correlação das facies estratigráficas, baseadas na descrição dos testemunhos da planície costeira de Soure, permitiram a visualização geral da distribuição dos ambientes deposicionais e sua sucessão temporal. Com os dados obtidos, foi possível construir seções estratigráficas da porção proximal (interna), distal (externa) e transversal da planície costeira, retratando uma visão esquemática da morfologia de sub- 
superfície, bem como de suas relações laterais (Figuras 3, 4 e 5). $\mathrm{O}$ número de perfis e a profundidade alcançada não foram suficientes para um estudo mais completo do pacote sedimentar depositado durante o Holoceno, sendo possível caracterizar apenas as sucessōes estratigráficas superficiais.

A história sedimentar holocênica da planície costeira de Soure, é representada por duas sucessōes estratigráficas: progradacional e retrogradacional (Figura 6).

A sucessão progradacional é caracterizada por: (1) facies com acamamento heterolítico lenticular, wave e flaser, marcas onduladas, lamas stripe lamination e lamas negras laminadas paralelamente, atribuídas a depósitos influenciados por maré (ambientes de planície de supramaré, intermaré e inframaré e barra de canal de maré); e (2) facies de lama cinza escura a negra, com abundância de restos orgânicos, relativas a ambientes de manguezal, situadas em geral no topo dos testemunhos (Figuras $3,4,5$ e 6$)$.

A sucessão progradacional desenvolveu-se sob condiçōes de mar alto ou regressivo, no Holoceno médio e superior, tendo como resultado a progradação sub-aérea e o avanço da linha de costa em direção à baía de Marajó. A sedimentação, nesse período, foi principalmente lamosa controlada por processos de maré, o que justifica o predomínio das estruturas heterolíticas lenticular, wave e flaser, o desenvolvimento de depósitos de manguezal, e as sucessões de facies granodecrescentes ascendentes.

A fase acrecional foi interrompida, algumas vezes, por curtas fases erosionais ou retrogradacionais, com mudanças nas condições



Figura 3 - Seção estratigráfica da porção proximal (interna) da planície costeira de Soure. energéticas dos ambientes e no suprimento sedimentar, que acarretaram novo retrabalhamento dos sedimentos costeiros e sedimentação arenosa, propiciando a formação de cordōes de praia, bordejando as planícies de maré. Posteriormente, a retomada da progradação lamosa, devido ao retorno das condiçôes ambientais anteriores, produziu o isolamento desses cordóes arenosos (cheniers). Isso explica a presença de facies lamosas ou com acamamento heterolítico sobrepostas a facies de areia fina com estrutura plano-paralela a inclinada, nos testemunhos TC, TP2 e TA, indicando a ocorrência de cordōes praiais que marcam antigas linhas de costa, posicionadas paralelamente ou subparalelamente e a distâncias variadas em relação à costa atual.

As facies da porção interna da planície costeira são constituídas por sedimentos mais finos (silte/argila e areia fina), relativas a regiōes de mais baixos níveis de energia. Na porção externa, os depósitos refletem o aumento das condiçōes energéticas relacionadas à maior velocidade das correntes de maré e ao maior tempo de atuação das ondas, caracterizados pela presença de facies mais arenosas.

A sucessão progradacional da planície costeira de Soure é condizente com a sucessão regressiva ou de mar estável (S2), do



Figura 4 - Seção estratigráfica da porção distal (externa) da planície costeira de Soure.

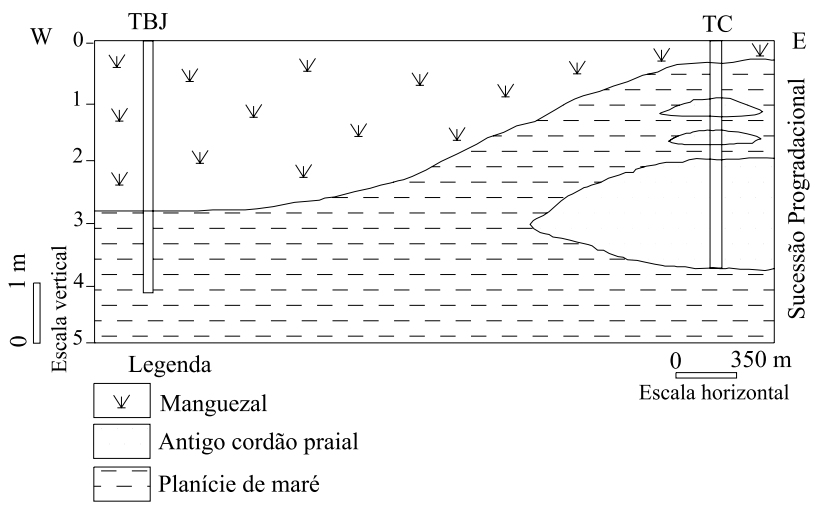

Figura 5 - Seção estratigráfica transversal da planície costeira de Soure. 
modelo deposicional proposto para as planícies costeiras de Bragança, Salinópolis, Marapanim e São João de Pirabas, baseado em estudos morfoestratigráficos (Souza Filho, 1995; Silva, 1996; Souza Filho \& El-Robrini, 1998; Silva, 1998; Silva Júnior \& El-Robrini, 2001), ou condizente com o episódio transgressivo marinho, do Holoceno superior, descrito por Behling \& Costa (2001) e Senna \& Absy (2002), através de estudos palinológicos, que registraram uma expansão dos manguezais com diversidade de espécies, nos litorais de Marapanim e Magalhães Barata.

A sucessão retrogradacional sobrepóe-se à sucessão progradacional na porçâo distal da planície costeira. É constituída por facies arenosas, de cor cinza clara a esbranquiçada, com estratificação plano-paralela a inclinada, ou sem estratificação aparente, representativas de praias-barreiras e dunas atuais (Figuras 4 e 6).

$\mathrm{Na}$ parte sul da planície de Soure, representada pelo testemunho TG, as condiçóes ambientais de maior energia e o maior suprimento arenoso retratam pulsos de sobreposição da planície de maré pelo ambiente praial e de duna, intercalando depósitos de planície de infra, inter e supramaré e leques de lavagem. A transposição da praia-barreira está relacionada a um outro processo, já registrado em vários setores da costa paraense, e que se caracteriza pela migração dos lençóis arenosos praiais sobre os ambientes lamosos de maré e assoreamento de desembocaduras (retrogradação costeira). Esse fenômeno é vinculado a uma provável subida do nível do mar, gerando depósitos transgressivos (Souza Filho, 1995). A sucessão retrogradacional corresponde à sucessão transgressiva atual (S3), do modelo de sedimentação das planícies costeiras do nordeste do Pará (Souza Filho, 1995; Silva, 1996; Souza Filho \& ElRobrini, 1998; Silva, 1998; Silva Júnior \& El-Robrini, 2001).

O estudo sobre o modelo sedimentar da planície costeira de Soure, requer pesquisas mais amplas, que incluam amostragens

\begin{tabular}{|c|c|c|c|c|}
\hline \multicolumn{3}{|r|}{ AMBIENTE } & SEDIMENTOLOGIA & SEQÜÊNCIA \\
\hline & \multicolumn{2}{|c|}{$\begin{array}{l}\text { Cordão arenoso de } \\
\text { praia e duna atual }\end{array}$} & $\begin{array}{l}\text { Areia fina, estratificação } \\
\text { plano-paralela a } \\
\text { inclinada de baixo } \\
\text { ângulo }\end{array}$ & 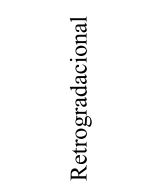 \\
\hline $\begin{array}{ll}v & 2 \\
x & v \\
x & v\end{array}$ & & Manguezal & $\begin{array}{l}\text { Lama cinzza escura a negra, } \\
\text { acamamento plano-paraleloa } \\
\text { macico, abundancia de raizes e } \\
\text { outros fragmentos de materia } \\
\text { organica. }\end{array}$ & 氶 \\
\hline$\left[\begin{array}{l}-2 \\
--\end{array}\right]$ & & $\begin{array}{l}\text { Planície de } \\
\text { supra, intermaré e } \\
\text { inframaré }\end{array}$ & $\begin{array}{l}\text { Acamamento heterolitico flaser, } \\
\text { wave ele teticular, laminacáa plano- } \\
\text { paralela a inclinada de baixo ângulo, } \\
\text { marcas onduladas, lama cinza } \\
\text { stripe lamination, argilito negro } \\
\text { laminado paralelamente. }\end{array}$ & 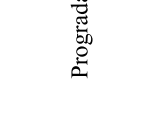 \\
\hline
\end{tabular}

Figura 6 - Coluna estratigráfica da planície costeira de Soure. mais profundas, análises polínicas e datações, a fim de que se possa produzir uma melhor compreensão da evoluçãa ambiental, durante o Holoceno.

\section{CONCLUSÕES}

A interpretação do processo de sedimentação da planície costeira de Soure baseou-se nas descrições estratigráfica de testemunhos a vibração e de afloramentos de campo, na análise da associação de facies e da sucessão de ambientes deposicionais, durante o Holoceno, o que permitiu a elaboração de seçōes estratigráficas das porções proximal, distal e transversal da planície costeira, além de uma coluna estratigráfica.

Com base na estrutura sedimentar, na cor e na granulometria, foi possível distinguir cinco associações de facies estratigráficas: facies de planície de maré, facies de manguezal, facies de barra de canal de maré, facies de praia e facies de duna. As associaçōes de facies definem vários ambientes sedimentares, produtos de diferentes processos deposicionais: planície de maré (supramaré, intermaré e inframaré), manguezal, barra de margem de canal, praia-barreira e duna.

A estratigrafia holocênica, da planície costeira de Soure, é representada pelas sucessóes progradacional e retrogradacional. A sucessão progradacional foi depositada sob condiçōes de mar alto ou regressivo, que acarretou o avanço da linha de costa em direção à baía de Marajó. É constituída por facies heterolíticas lenticular, wave eflaser, por facies lamosas cinzas-escuro a negra, com estratificação paralela e stripe lamination, abundância de fragmentos orgânicos. Refletem processos controlados pela variação de velocidade das correntes de maré, resultando em depósitos de planície de maré e manguezal.

A sucessão retrogradacional foi depositada sob condições transgressivas atuais, relacionadas a uma possível elevação do nível relativo do mar. É constituída por facies arenosas com acamamento plano a inclinado, representativas de ambientes de praias-barreiras e dunas, cujos processos deposicionais são controlados pelo tempo de atuação das ondas e dos ventos da baía de Marajó, PA. Esta sucessão sobrepõe-se à sucessão progradacional, refletindo a migração dos cordōes arenosos de praias e dunas sobre os depósitos de manguezal.

O modelo de sedimentação da planície costeira de Soure é condizente com o modelo proposto para as planícies costeiras do nordeste do Estado do Pará. É correlacionável à sucessão regressiva ou de mar estável (S2) e à sucessão transgressiva atual (S3), que retratam uma fase de expansão dos manguezais, no Holoceno médio a superior, e uma posterior fase de retração, representada pela superposição dos ambientes praiais e dunares, no Holoceno superior.

Dada a complexidade dos fatores geológicos e dos processos que atuaram ao longo do tempo, as idéias expressas sobre a 
sedimentação holocênica da planície costeira de Soure não são conclusivas. Estudos mais criteriosos deverão ser realizados a fim de fornecer dados mais completos para a discussão e a elucidação da história ambiental da margem leste da ilha de Marajó.

\section{BIBLIOGRAFIA CITADA}

Behling, H.; Costa, M.L. 2001. Holocene vegetational and coastal environmental changes from the lago Crispim record in northeastern Pará State, eastern Amazonia. Review of Palaeobotany and Palinology, 114: 145-155.

Dalrymple, R.W. 1992. Tidal depositional systems. In: Walker, R.G.; James, N.P. (orgs.). Facies models. Response to sea level change. Geologial Association of Canada. Ontario. p. 195-219.

DHN. 2001. Tábua das Marés. Marinha do Brasil. Disponível em: http://www.mar.mil.br. Acesso em: 3 fev. 2001; 20 fev. 2001; 13 jun. 2001; 30 ago. 2001; 5 nov. 2001.

Figueiredo Júnior, A.G. 1990. Normas de controle de qualidade para processamento de testemunhos inconsolidados. In: PETROBRÁS. Projeto Sedimentos de Talude. Rio de Janeiro, UFF. 27 p. (Contrato PETROBRÁS/UFF n.o 3-570-794-090).

Lisboa, P.L.B.; Lisboa, R.C.L.; Rosa, N.A.; Santos, M.R. 1993. Padrões de diversidade florística na Reserva Ecológica do Bacurizal, em Salvaterra, ilha do Marajó, Pará. Boletim do Museu Paraense Emílio Goeldi, 9 (2): 223-248.

Reineck, H-E.; Singh, I.B. 1980. Depositional Sedimentary Environments. 2. ed. Springer-Verlag. New York. 543pp.

Reinson, G.E. 1992. Trangressive barrier island and estuarine systems. In: Walker, R.G.; James, N.P. (orgs.). Facies models. Response to sea level change. Ontario, Geologial Association of Canada. p. 179-194.
Santos, V.F. 1996. Estratigrafia holocênica e morfodinâmica atual da planície costeira da ilha de Algodoal e Marudá. Dissertação de Mestrado. Universidade Federal do Pará, Belém, PA. 128pp.

Senna, C.; Absy, M.L. 2002. Registros palinológicos de manguezais do Quaternário da costa norte da América do Sul. In: Workshop ECOLAB, 6., Belém.1 CD-ROM. (Trabalhos completos).

Silva, C.A. 1998. Análise morfoestratigráfica do estuário do rio Marapanim - NE do Pará. Dissertação de Mestrado, Universidade Federal do Pará. Centro de Geociências. Belém. 133 p.

Silva, M.S. 1996. Morfoestratigrafia e evolução holocênica da planície costeira de Salinópolis, nordeste do Estado do Pará. Belém, Universidade Federal do Pará. Centro de Geociências. 145 p. (Dissertação de Mestrado).

Silva Júnior, O.G.; El-Robrini, M. 2001. Morfoestratigrafia do noroeste da planície costeira de São João de Pirabas (nordeste do Pará). Revista Brasileira de Oceanografia, 49 (1/2) : 99-114.

Souza Filho, P.W.M. 1995. A planicie costeira bragantina (NE do Pará): influência das variações do nível do mar na morfoestratigrafia costeira durante o Holoceno. Universidade Federal do Pará. Centro de Geociências. Belém. 122 p.

Souza Filho, P.W.M. \& El-Robrini, M. 1996. Morfologia, processos de sedimentação e litofácies dos ambientes morfo-sedimentares da planície costeira Bragantina, nordeste do Pará, Brasil. Geonomos, 4 (2): 1-16.

Souza Filho, P.W.M.; El-Robrini, M. 1998. As variaçôes de nível relativo do mar e a estratigrafia de seqüências da planície costeira bragantina, nordeste do Pará, Brasil. Boletim do Museu Paraense Emílio Goeldi, 10: 45-78.

Recebido em 09/03/2005

Aceito em 26/03/2007 